\title{
Symmetric pollen mitosis I and suppression of pollen mitosis II prevent pollen development in Brachiaria jubata (Gramineae)
}

\section{Risso-Pascotto ${ }^{1}$, M.S. Pagliarini, \\ C.B. Valle ${ }^{2}$ and L. Jank ${ }^{2}$}

\author{
${ }^{1}$ Departamento de Biologia Celular e Genética, \\ Universidade Estadual de Maringá, Maringá, PR, Brasil \\ ${ }^{2}$ Embrapa Gado de Corte, Campo Grande, MS, Brasil
}

\section{Correspondence \\ M.S. Pagliarini \\ Departamento de Biologia Celular \\ e Genética \\ Universidade Estadual de Maringá \\ 87020-900 Maringá, PR \\ Brasil \\ E-mail: mspagliarini@uem.br \\ Presented at the XI Congresso Brasileiro de Biologia Celular, Campinas, SP, Brazil, July 15-18, 2004.}

Received June 1, 2004

Accepted April 29, 2005

\begin{abstract}
Microsporogenesis and pollen development were analyzed in a tetraploid $(2 \mathrm{n}=4 \mathrm{x}=36)$ accession of the forage grass Brachiaria jubata (BRA 007820) from the Embrapa Beef Cattle Brachiaria collection that showed partial male sterility. Microsporocytes and pollen grains were prepared by squashing and staining with $0.5 \%$ propionic carmine. The meiotic process was typical of polyploids, with precocious chromosome migration to the poles and laggards in both meiosis I and II, resulting in tetrads with micronuclei in some microspores. After callose dissolution, microspores were released into the anther locule and appeared to be normal. Although each microspore initiated its differentiation into a pollen grain, in $11.1 \%$ of them nucleus polarization was not observed, i.e., pollen mitosis I was symmetric and the typical hemispherical cell plate was not detected. After a central cytokinesis, two equal-sized cells showing equal chromatin condensation and the same nuclear shape and size were formed. Generative cells and vegetative cells could not be distinguished. These cells did not undergo the second pollen mitosis and after completion of pollen wall synthesis each gave rise to a sterile and uninucleate pollen grain. The frequency of abnormal pollen mitosis varied among flowers and also among inflorescences. All plants were equally affected. The absence of fertile sperm cells in a considerable amount of pollen grains in this accession of B. jubata may compromise its use in breeding and could explain, at least in part, why seed production is low when compared with the amount of flowers per raceme.
\end{abstract}

\section{Introduction}

The events that culminate in the formation of the pollen grain involve an intricate and tightly controlled set of structural and molecular gene expression events in both the
Key words

- Brachiaria jubata

- Male sterility

- Microgametogenesis

- Pollen mitosis

- Sperm cell gametophytic and sporophytic tissues of the anther. Firstly, pollen mother cells undergo meiosis, giving rise to a tetrad of haploid cells. The individual cells of the tetrad are released as free microspores by the action of callase, an enzyme produced by the tapetum 
layer of the anther (1).

After an initial burst of growth and exine synthesis, the haploid microspores undergo cytological reorganization in preparation for a key event in pollen development, i.e., the asymmetric mitotic division (2). This mitotic division, also known as 'pollen mitosis one' (PM I), results in the formation of two dimorphic cells, the vegetative cell and the generative cell, with very different fates (1-5). The smaller generative cell produces two sperm cells (male gametes) after 'pollen mitosis two' (PM II), whereas the larger vegetative cell, which constitutes the bulk of the pollen grain, produces an elongated pollen tube (a gametophytic cell) to deliver the male gametes to the embryo sac (5). The generative/sperm cells have very little cytoplasm and sparse nuclear chromatin, suggesting that they have lower transcriptional activity (6).

Defective mutants operating at various stages of microspore development have been reported in Arabidopsis (7-16) and maize (17-20). In Brachiaria decumbens c.v. Basilisk, a variety extensively used for forage in Brazil, a possible mutation affecting pollen development has been recently reported (21). In the current paper we describe an abnormal pollen mitosis division in one accession of Brachiaria jubata, a species of interest in the forage breeding program.

\section{Material and Methods}

Cytogenetic studies were carried out on the BRA 007820 accession of $B$. jubata from the Embrapa Beef Cattle Brachiaria collection kept in Campo Grande (State of Mato Grosso do Sul, Brazil), which comprises 475 accessions of 15 species.

Inflorescences for microsporogenesis and microgametogenesis studies were collected and fixed in a mixture of $95 \%$ ethanol, chloroform and propionic acid (6:3:1) for $24 \mathrm{~h}$, transferred to $70 \%$ alcohol and stored under refrigeration until use. Microsporocytes and pollen grains were prepared by squashing and staining with $0.5 \%$ propionic carmine. All meiotic phases and stages of pollen development were evaluated in inflorescences

Table 1. Frequency of abnormalities recorded in Brachiaria jubata pollen during microsporogenesis.

\begin{tabular}{|c|c|c|c|c|}
\hline Phase & $\begin{array}{l}\text { No. of cells } \\
\text { analyzed }\end{array}$ & $\begin{array}{l}\text { No. of abnormal } \\
\text { cells }(\%)\end{array}$ & Abnormalities & $\begin{array}{l}\text { No. of } \\
\text { cells }\end{array}$ \\
\hline Metaphase I & 155 & 52 (33.55) & $\begin{array}{l}\text { Precocious chromosome migration } \\
\text { Fusion }\end{array}$ & $\begin{array}{r}46 \\
6\end{array}$ \\
\hline Anaphase I & 172 & $45(26.16)$ & $\begin{array}{l}\text { Laggard chromosomes } \\
\text { Fusion }\end{array}$ & $\begin{array}{r}43 \\
2\end{array}$ \\
\hline Telophase I & 158 & $15(9.50)$ & $\begin{array}{l}\text { Micronuclei } \\
\text { Fusion }\end{array}$ & $\begin{array}{r}13 \\
2\end{array}$ \\
\hline Prophase II & 161 & 22 (13.66) & $\begin{array}{l}\text { Micronuclei } \\
\text { Microcytes }\end{array}$ & $\begin{array}{r}18 \\
4\end{array}$ \\
\hline Metaphase II & 245 & $63(25.71)$ & $\begin{array}{l}\text { Precocious chromosome migration } \\
\text { Microcytes }\end{array}$ & $\begin{array}{r}54 \\
9\end{array}$ \\
\hline Anaphase II & 155 & $26(16.77)$ & $\begin{array}{l}\text { Laggard chromosomes } \\
\text { Microcytes }\end{array}$ & $\begin{array}{r}24 \\
2\end{array}$ \\
\hline Telophase II & 154 & $13(8.44)$ & $\begin{array}{l}\text { Micronuclei } \\
\text { Microcytes }\end{array}$ & $\begin{array}{l}8 \\
5\end{array}$ \\
\hline Meiotic product & 158 & $22(13.92)$ & $\begin{array}{l}\text { Tetrad with micronuclei } \\
\text { Tetrad with microcytes }\end{array}$ & $\begin{array}{r}18 \\
4\end{array}$ \\
\hline
\end{tabular}


collected from four plants of this accession obtained by vegetative propagation. Photomicrographs were obtained with a Wild Leitz microscope using Kodak Imagelink-HQ, ISO 25 black and white film.

\section{Results}

Cytological characterization of the accession was carried out from meiosis to pollen formation. The chromosome number scored at diakinesis revealed tetraploidy $(2 \mathrm{n}$ $=4 \mathrm{x}=36$ ). The meiotic process was typical of polyploids (Table 1), with chromosomes associating in bi-, tri-, and quadrivalents. Precocious chromosome migration to the poles, laggards and micronucleus formation were found in both meiosis I and II, resulting in tetrads with micronuclei in some microspores (Figure 1a). After callose dissolution, microspores were released into the an- ther locule and seemed to be normal. Each microspore then initiated PM I. In most microspores, pollen mitosis developed normally, with the characteristic polarization of the nucleus and its subsequent asymmetric division (Figure 1b) into two unequal cells (Figure 1c). However, in $11.1 \%$ of the microspores, after callose dissolution (Figure 1d), the released microspores underwent symmetric pollen mitosis, i.e., the nucleus was not displaced from the cell center to one side of the cell (Figure 1e). The typical hemispherical cell plate, like that observed in normal pollen grains (Figure 1c), was not seen in these cases, and all mitotic stages from prophase to telophase occurred without polarization (Figure 1f and g). After cytokinesis, two equal-sized cells were observed as a result of symmetric division (Figure 1h). Both cells also showed equal chromatin condensation and the nuclei had

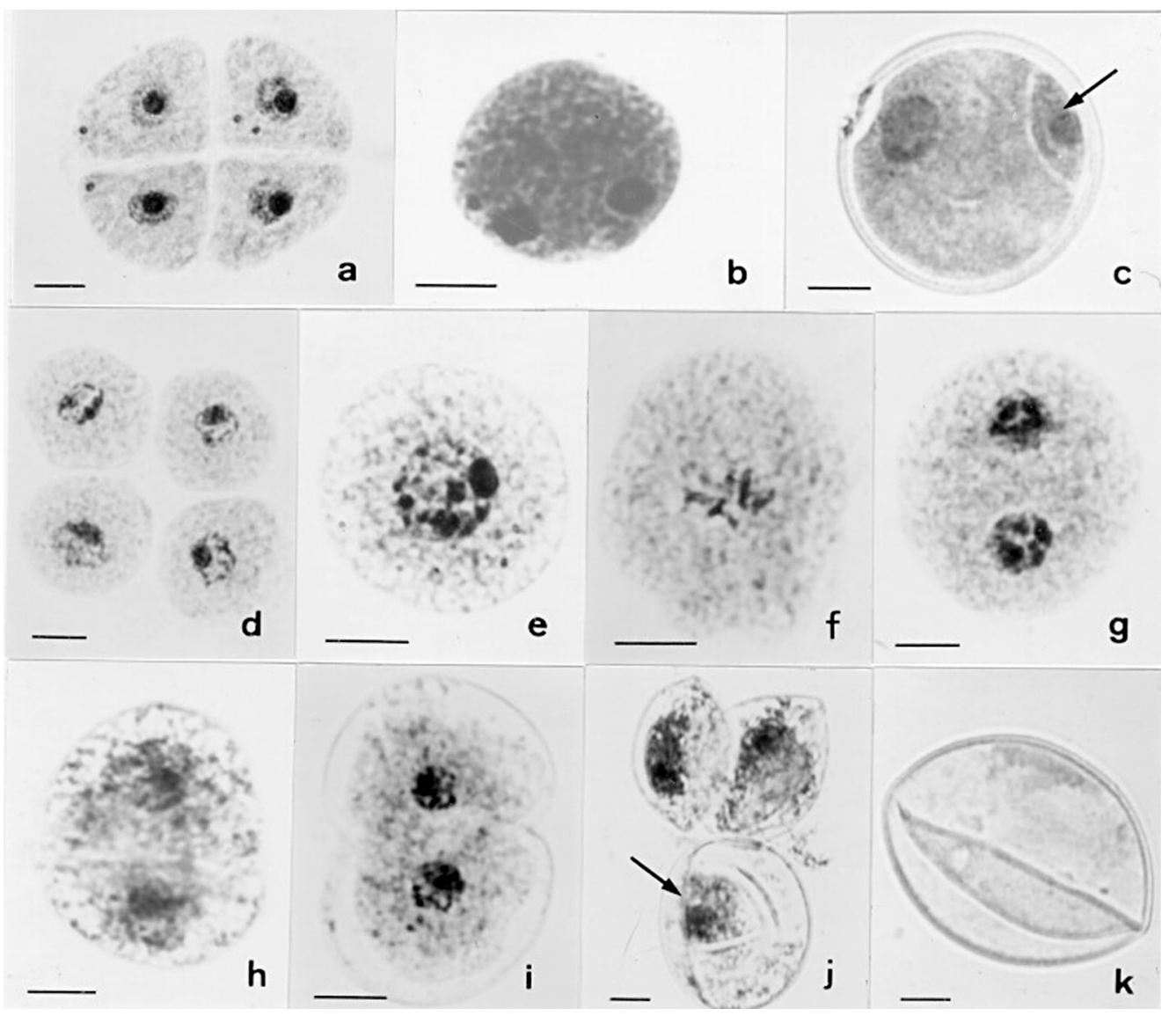

Figure 1. Pollen development in Brachiaria jubata (BRA 007820). $a$, Normal tetrad with several micronuclei in microspores. $b$, Normal pollen mitosis (PM I): telophase. Note the polarized nucleus position. $c$, Pollen grain after a normal and asymmetric PM I. Observe the typical hemispherical cell plate between the generative (arrow) and the vegetative cells. $d$, Tetrad after callose dissolution. e, Abnormal released microspore without nucleus polarization. $\mathrm{f}, \mathrm{g}$, Symmetric PM I: metaphase ( $f$ ) and telophase $(\mathrm{g})$. Observe the lack of displacement of cell division from the cell center. In telophase (g), note that both nuclei are of equal sizes and chromatin is equally condensed. $h$, Cytokinesis after telophase dividing the microspore into two equal-sized cells. $i$, Two uninucleate sister pollen grains. $j$, Two sister pollen grains flanked by a normal one (arrow). Note that the normal pollen grain is double the size of those resulting from symmetric PM I. $k$, Sterile pollen grain. (Scale bars $=0.5 \mu \mathrm{m}$ ). 
the same spherical shape and were of equal sizes (Figure 1h), i.e., the generative nucleus and vegetative nucleus could not be differentiated. After this stage, each cell developed into a pollen grain (Figure 1i). These cells did not undergo PM II and completed the synthesis of the pollen wall (Figure 1j). Each pollen grain was half the size of a normal pollen grain (Figure $1 \mathrm{j}$ ). The frequency of abnormal pollen mitosis varied among flowers and also among inflorescences. All plants were equally affected. Sterile pollen grains resulted from this abnormal pollen development (Figure 1k). Pollen sterility, however, was much higher due to abnormal chromosome segregation caused by polyploidy.

\section{Discussion}

The pollen grain is released from the anther when it consists of just generative and vegetative cells in approximately $70 \%$ of plant families, and therefore PM II occurs while the pollen tube grows through the female pistil. In other plant families, including the Gramineae, this second mitotic division occurs before the pollen is shed from the plant (1). Therefore, in the genus Brachiaria, normal pollen production should display this mitosis before pollen shedding from the anther. In the accession of B. jubata under analysis, abnormal pollen mitosis (PM I) impaired the generative and vegetative cell differentiation, and the absence of PM II prevented sperm cell formation in over 10\% of the microspores, causing pollen sterility.

Pollen development and male gametogenesis are critically dependent upon cell polarization which contributes to a highly asymmetric cell division (PM I). In normal microspores, the nucleus is displaced from the cell center to one side of its long axis at the $G_{1}$ phase of the microspore cell cycle. Displacement continues throughout the mitotic cycle (22) and the nucleus polarization is maintained by the microtubule cytoskel- eton (4). In the present accession, displacement of the nucleus did not occur in abnormal microspores. A similar behavior was also reported to occur naturally in $B$. decumbens (21), whereas the symmetric divisions observed in Tulipa gesneriana (23), tobacco (24), and Arabidopsis (15) were induced.

Asymmetric cell division relies on the formation of a typical hemispherical cell plate, in which spindle orientation is very important for normal differentiation of the generative and vegetative cells (25). An asymmetric, cone-shaped spindle perpendicular to the plasma membrane appears in this division $(26,27)$. The generative pole lies adjacent to the plasma membrane and the vegetative pole is located in the inner cytoplasm of the microspore. In the present study, a hemispherical cell plate was not recorded in the first pollen mitosis of this B. jubata accession, as also reported by Junqueira Filho et al. (21) for a $B$. decumbens accession. Tanaka (4) postulated that microtubules are involved in nuclear displacement and in the maintenance of the nuclear position of the hemispherical phragmoplast, and both are prerequisites for asymmetric cell division in microspores. Based on this assumption, we suggest that the abnormal plants found in both Brachiaria species display anomalies in microtubule organization since nuclear displacement did not occur, nor was the hemispherical cell plate formed.

In normal plants, the vegetative and generative cells have different structures and developmental fates $(4,15,28)$. While the large vegetative cell accumulates an abundance of stored metabolites required for rapid pollen tube extension, the smaller cell is enclosed by vegetative cell cytoplasm and contains relatively few organelles and stored metabolites. A peculiar feature of the abnormal microspores of $B$. jubata, similar to the abnormal microspores of $B$. decumbens reported by Junqueira Filho et al. (21), was the lack of differentiation between the vegetative and the generative cell. Both were of 
equal sizes. According to Tanaka (4), when the asymmetric cell division is inhibited or altered into a symmetric division, differentiation of the generative cell is prevented, and a cell-within-a cell is never formed thereafter. This might indicate that there is an intimate relationship between asymmetric cell division and the subsequent fates of the two daughter cells. In B. jubata, the lack of differentiation between the two daughter cells resulting from the first pollen mitosis compromised the pollen fate. After an evident cytokinesis among them, PM II did not occur, and each cell immediately differentiated into pollen grains. Thus, two half-sized pollen grains with a single nucleus were originated from each microspore. In contrast, in the abnormal microspore of $B$. decumbens reported by Junqueira Filho et al. (21), the two daughter cells underwent another symmetric pollen mitosis after symmetric PM I, the result being four uninucleate and sterile pollen grains at the end of PM II. The occurrence of PM II in B. decumbens (21) is the main differential characteristic between the two Brachiaria species.

Another characteristic of PM I for both Brachiaria species is the similar chromatin condensation in both resulting cells, i.e., there is no difference between the nuclei. In normal asymmetric PM I division, the nuclei of the generative cell and the vegetative cell respectively contain diffuse and highly condensed chromatin, visible just after PM I. Such striking difference in the structure of chromatin is assumed to be associated with the difference in gene activity between the two types of nuclei, the generative cell nucleus being less transcriptionally active than the vegetative one (29). The absence of chromatin differentiation between nuclei resulting from PM I in B. jubata suggests that both are equally active.

The production of a functional pollen grain involves a complex series of regulated processes and requires the expression of a large number of sporophytic and gameto- phytic genes (20). First pollen mitosis appears to be a critical point for gametophytic development (1), because a specific set of genes is activated at this time. Mutations that affect the nuclear division pattern at the gametophytic stage have been scarcely registered $(15,16,20,30,31)$. An abnormality similar to that found in the present accession of $B$. jubata causing symmetric PM I and suppressing PM II has not been described in other species. This abnormality was not regularly expressed in the microsporocytes of all flowers or inflorescences examined. Only $11.1 \%$ of the microspores presented abnormal pollen mitosis. An incompletely penetrant phenotype resulting in equal, unequal and partial divisions at PM I has been reported in the gametophytic mutation gemini pollen1 of Arabidopsis thaliana (15), and in B. decumbens (21), both disrupting microspore polarity, division asymmetry and pollen cell fate.

For double fertilization in angiosperms, two sperm cells are necessary. One sperm cell fuses with the egg cell to form the embryo and the other fuses with the central cells to form the endosperm. Abnormalities that cause male sterility in plants are considered to be of great interest in breeding programs because they might prevent self-pollination of sexual genitors but also cause lack of seed set in genotypes with important breeding traits. The Brachiaria breeding program aims at producing hybrids by intra- and interspecific crosses using sexual accessions or hybrids as mother plants and apomictic accessions as pollen parents. Polyploid accessions of Brachiaria are pseudogamous (apomictic), which means that the centralcell nucleus needs to be fertilized for endosperm and healthy seed development, even though the egg cell is not fertilized in an aposporous embryo sac. The absence of fertile sperm cells in a considerable amount of pollen grains in this apomictic accession of B. jubata, caused by symmetric pollen mitosis (PM I), added to the unbalanced gametes 
generated by irregular chromosome segregation during meiosis due to polyploidy, may compromise its use in breeding and could explain, at least in part, why seed production is low when compared with the amount of flowers per raceme.

\section{References}

1. McCormick S (1993). Male gametophyte development. Plant Cell, 5: 1265-1275.

2. Bedinger P (1992). The remarkable biology of pollen. Plant Cell, 4: 879-887.

3. Horvitz HR \& Herskowitz I (1992). Mechanisms of asymmetric cell division: Two Bs or not two Bs, that is the question. Cell, 68: 237255.

4. Tanaka I (1997). Differentiation of generative and vegetative cells in angiosperm pollen. Sexual Plant Reproduction, 10: 1-7.

5. Saito C, Fujie M, Sakai A et al. (1998). A high density of rRNA in the generative cells and sperm cells of pollen grains of five angiosperm species. Cytologia, 63: 293-300.

6. Saito C, Fujie M, Sakai A et al. (1997). Extent of the condensation of nuclear chromatin and the localization of RNA during pollen development in Nicotiana tabacum. Cytologia, 62: 121-132.

7. Regan SM \& Moffat BA (1990). Cytochemical analysis of pollen development in wild-type Arabidopsis and a male-sterile mutant. Plant Cell, 2: 877-889.

8. Preuss D, Bemieux B, Yen G et al. (1993). A conditional sterile mutation eliminates surface components from Arabidopsis pollen and disrupts cell signaling during fertilization. Genes and Development, 7: 974-985.

9. Dawson J, Wilson ZA, Aarts MGM et al. (1993). Microspore and pollen development in six male-sterile mutants of Arabidopsis thaliana. Canadian Journal of Botany, 71: 629-638.

10. Hülskamp M, Kopczak SD, Horejsi TF et al. (1995). Identification of genes required for pollen-stigma recognition in Arabidopsis thaliana. Plant Journal, 8: 703-714.

11. He C, Tirlapur U, Cresti M et al. (1996). An Arabidopsis thaliana mutant showing aberrations in male meiosis. Sexual Plant Reproduction, 9: 54-57.

12. Peirson BN, Owen HA, Feldmann KA et al. (1996). Characterization of three male-sterile mutants of Arabidopsis thaliana exhibiting alterations in meiosis. Sexual Plant Reproduction, 9: 1-16.

13. Rhee SY \& Somerville CR (1998). Tetrad pollen formation in quartet mutants of Arabidopsis thaliana is associated with persistence of pectic polysaccharides of the pollen mother cell wall. Plant Journal, 15: 79-88.

14. Taylor PE, Glover JA, Lavithis M et al. (1998). Genetic control of male fertility in Arabidopsis thaliana: structural analyses of postmeiotic developmental mutants. Planta, 205: 492-505.

15. Park SK, Howden R \& Twell D (1998). The Arabidopsis thaliana gametophytic mutation gemini pollen1 disrupts microspore polarity, division asymmetry and pollen cell fate. Development, 125: 37893799.

16. Park SK \& Twell D (2001). Novel patterns of ecotopic cell plate growth and lipid body distribution in the Arabidopsis gemini pollen1 mutant. Plant Physiology, 126: 899-909.

17. Albertson MC \& Phillips RL (1981). Developmental cytology of 13 genetic male sterile loci in maize. Canadian Journal of Genetics and Cytology, 23: 195-208.

18. West DP \& Phillips RL (1985). Polymitotic: supernumerary repetitions of meiosis II. Maize Genetics Cooperation News Letter, 59: 106-107.

19. Liu Q, Golubovskaya IN \& Cande WZ (1993). Abnormal cytoskeletal and chromosome distribution in po, $m s 4$ and $m s 6$; mutant alleles of polymitotic that disrupt the cell cycle progression from meiosis to mitosis in maize. Journal of Cell Science, 106: 1169-1178.

20. Sari-Gorla M, Gatti E, Villa M et al. (1997). A multi-nucleate malesterile mutant of maize with gametophytic expression. Sexual Plant Reproduction, 10: 22-26.

21. Junqueira Filho RG, Mendes-Bonato AB, Pagliarini MS et al. (2003). Absence of microspore polarity, symmetric divisions and pollen cell fate in Brachiaria decumbens (Gramineae). Genome, 46: 83-88.

22. Tanaka I, Taguchi T \& Ito M (1979). Studies on microspore development in liliaceous plants. I. The duration of the cell cycle and developmental aspects in lily microspores. Botanical Magazine, 92: 291298.

23. Tanaka I \& Ito M (1981). Control of division patterns in explanted microspores of Tulipa gesneriana. Protoplasma, 108: 329-340.

24. Eady C, Lindsey K \& Twell D (1995). The significance of microspore division and division symmetry for vegetative cell-specific transcription and generative cell differentiation. Plant Cell, 7: 65-74.

25. Heslop-Harrison J (1968). Synchronous pollen mitosis and the formation of generative cell in massulate orchids. Journal of Cell Science, 3: 457-466.

26. Brown RC \& Lemon BE (1991). Pollen development in orchids. 3. A novel generative pole microtubule system predicts unequal pollen mitosis. Journal of Cell Science, 99: 273-281.

27. Brown RC \& Lemon BE (1992). Pollen development in orchids. 4. Cytoskeleton and ultrastructure of the unequal pollen mitosis in Phalaenopsis. Protoplasma, 167: 183-192.

28. Twell D, Park SK \& Lalanne E (1998). Asymmetric division and cellfate determination in developing pollen. Trends in Plant Sciences, 3: 305-310.

29. Tanaka I, Ono K \& Fukuda T (1998). The developmental fate of angiosperm pollen is associated with a preferential decrease in the level of histone $\mathrm{H} 1$ in the vegetative nucleus. Planta, 206: 561-569.

30. Xu H, Knox RB, Taylor PE et al. (1995). Bcp 1, a gene required for male fertility in Arabidopsis. Proceedings of the National Academy of Sciences, USA, 92: 2106-2110.

31. Sari-Gorla M, Ferrario S, Villa M et al. (1996). gaMS-1, a gametophytic expressed male sterile mutant of maize. Sexual Plant Reproduction, 9: 216-220. 